\title{
The Pune Rural Intervention in Young Adolescents (PRIYA) study: design and methods of a randomised controlled trial
}

\author{
Kalyanaraman Kumaran ${ }^{1,2}$, Pallavi Yajnik' , Himangi Lubree ${ }^{1}$, Charudatta Joglekar ${ }^{1}$, Dattatray Bhat ${ }^{1}$, Prachi Katre ${ }^{1}$, \\ Suyog Joshi ${ }^{1}$, Rasika Ladkat ${ }^{1}$, Caroline Fall ${ }^{2}$ and Chittaranjan Yajnik ${ }^{1 *}$ (D)
}

\begin{abstract}
Background: The Pune Maternal Nutrition Study (PMNS) was established to prospectively study the relationship of maternal nutrition to fetal growth and later cardiometabolic risk in the offspring. High homocysteine and low vitamin B12 levels in pregnancy predicted lower birthweight and higher insulin resistance at 6 years in the offspring. B12 deficiency was widespread in this population, due to low dietary intake. We therefore commenced a community-based intervention study with the underlying hypothesis that vitamin B12 supplementation of adolescent members of the PMNS cohort will improve birth weight, B12 status, and reduce future diabetes risk, in their offspring.

Methods: The individually randomised controlled trial commenced in September 2012, with boys and girls randomized into 3 groups, to receive daily for at least 3 years or until the birth of their first child: 1) vitamin B12 $2 \mu \mathrm{g}$; or 2) vitamin B12 $2 \mu \mathrm{g}$ plus multiple micronutrients (MMN) plus $20 \mathrm{~g}$ of milk powder or 3) placebo. Iron and folic acid is given to all participants. Compliance is assessed by monthly supplement counts. Adverse events are recorded using a standardised questionnaire. The primary outcome is cord blood B12 concentration; based on 180-200 pregnancies in the girls, the study has $\sim 80 \%$ power to detect a 0.5 SD change in newborn B12, in the B12 supplementation groups compared with controls, at the $5 \%$ significance level. Primary analysis will be by intention to treat.

Discussion: Our study tests a primordial prevention strategy through an intergenerational intervention started preconceptionally in both boys and girls using physiological doses of micronutrients to improve immediate pregnancyrelated and long-term cardio metabolic outcomes. The results will have significant public health implications in a setting with widespread B12 deficiency but relative folate sufficiency. The randomised controlled trial design allows us to be confident that our findings will be causally relevant.
\end{abstract}

Trial registration: ISRCTN 32921044, applied on 14/09/2012. CTRI 2012/12/003212, registered on 02/12/2012. Retrospectively registered.

\section{Background}

Current preventive strategies to reduce the burden of type 2 diabetes mellitus (T2DM) focus mainly on improving the lifestyle of middle-aged individuals with pre-existing disease or risk factors. However, these measures can at best be termed secondary prevention and do not address the impact of the disease on future generations. So far, genetic research has also

\footnotetext{
* Correspondence: diabetes@kemdiabetes.org; csyajnik@gmail.com ${ }^{1}$ Diabetes Unit, KEM Hospital Research Centre, Rasta Peth, Pune 411011, India Full list of author information is available at the end of the article
}

failed to provide any major breakthrough towards primary prevention.

David Barker's 'fetal programming' hypothesis [1] suggests that alterations in the nutritional supply during critical stages of intrauterine growth permanently alter the structure and function of the fetal organs and offers a novel primary prevention strategy. This idea was based on findings, initially in the UK, that the prevalence of coronary heart disease, T2DM and impaired glucose tolerance was higher in adults who had lower birth weights [2]. Subsequently, these findings were replicated in different parts of the world, 
including India [3-7]. This suggested a possible role for fetal under-nutrition in the aetiology of these conditions. Postnatal growth is also associated with risk of T2DM; individuals with the highest risk are those who had a low birth weight but developed a high body mass index (BMI) as children or adults [8]. The fetal programming hypothesis was expanded to include postnatal factors and evolved into the 'developmental origins of health and disease' hypothesis (DOHaD).

The DOHaD hypothesis is supported by animal studies showing that obesity, hypertension and diabetes can be programmed by under- or over-nourishing the fetus by changing the pregnant mother's diet $[9,10]$. In contrast, evidence for $\mathrm{DOHaD}$ in humans is largely limited to observational studies using either extreme nutritional situations (eg. famine) or low birth weight as exposures, with little specific information on maternal nutrition. Follow up of children whose mothers participated in nutritional supplementation trials are limited. In India, offspring of mothers who were supplemented with energy and protein during pregnancy had lower insulin resistance and arterial stiffness in adolescence [11]. In Nepal, offspring of mothers who received multiple micronutrients (MMN) had lower blood pressure [12]. However, there were no effects on the body composition or blood pressure of offspring of women who received energy and protein supplementation in the Gambia [13].

Recent research suggests that programming effects may act through 'epigenetic' mechanisms that alter expression of genes without altering the DNA base sequence (i.e., they change the phenotype without changing the genotype). Epigenetic mechanisms may include changes in the methylation of DNA, modification (acetylation) of histones, and through miRNAs [14]. Animal studies have shown that nutritional interventions in pregnant mothers induce permanent changes in DNA methylation, gene expression, and later phenotype of the offspring $[15,16]$. Epigenetic studies in humans are limited but maternal nutrition has been shown to be associated with gene-specific differences in DNA methylation $[17,18]$, and DNA methylation in cord blood has been related to later adiposity $[19,20]$. Nutrients that are required for the activity of the 1-Carbon $(1-C)$ cycle, such as folate and vitamin B12, may be particularly relevant in relation to epigenetics, because the $1-C$ cycle generates methyl groups used in DNA methylation reactions. Research in The Gambia, where there is marked seasonal variation in maternal nutritional status, has shown that maternal levels of several 1-C-related nutrients around the time of conception are related to DNA methylation signatures in the children [21,22].

The DOHaD concept offers a paradigm shift in thinking about the aetiology, and therefore prevention, of diabetes and cardiovascular disease, and may be particularly applicable to the Indian situation characterised by a high burden of maternal malnutrition and low birth weight [23]. India is also one of the diabetes capitals of the world, with an estimated $\sim 72$ million people with T2DM in 2013, expected to rise to $\sim 123$ million by 2035 [24].

In 1993, we set up the Pune Maternal Nutrition Study (PMNS) in a rural community in western India to prospectively investigate the relationship between maternal nutrition and long-term cardiometabolic outcomes in the children. This study demonstrated a link between maternal micronutrient intake and offspring size; mothers who ate green leafy vegetables, fruit and milk more frequently, and who had higher red cell folate levels gave birth to heavier babies [25]. Maternal energy and protein intakes were unrelated to newborn size. When the Indian babies were compared to babies born in the UK, the Indian babies were $700 \mathrm{~g}$ lighter but had comparable subscapular skinfold thickness. Further studies using whole body MRI in the new-born confirmed that Indian babies have more abdominal fat at birth than English babies [26], and higher cord blood insulin and leptin concentrations [27]. This demonstrated that the 'thin-fat' Indian phenotype (a small body size with disproportionately high adiposity) [28] was present at birth and was not a consequence of post-natal life. Lower maternal B12 in pregnancy was also associated with higher maternal total homocysteine (tHcy) which predicted lower birth weight [29]. Mendelian Randomisation techniques analysing MTHFR genotypes predicting tHcy (C677T) suggested a possible causal link for the inverse association between tHcy concentrations and birth weight [30].

Higher folate concentrations in the mothers during pregnancy predicted greater adiposity in their children at 6 years of age [31]. Lower B12 in the pregnant mothers was associated with increased insulin resistance in their children; the highest insulin resistance was in children born to mothers with low B12 and high folate during pregnancy [31]. These findings were replicated in a study in Nepal [32]. About 70\% of PMNS mothers had low B12 status during pregnancy (plasma concentration $<150 \mathrm{pmol} / \mathrm{l}$ ) and $31 \%$ had a B12 concentration of $<100$ $\mathrm{pmol} / \mathrm{l}$. In contrast, less than $1 \%$ had low erythrocyte folate status $(<283 \mathrm{nmol} / \mathrm{l})$ while $30 \%$ had high homocysteine (tHcy) $(>10 \mu \mathrm{mol} / \mathrm{l})$ an indicator of deficiency of B12 or folate or imbalance of the two [29].

Subsequent work has shown that B12 deficiency in this community is due to low intakes, rather than to malabsorption [33]. A pilot intervention in the same community showed that B12 status can be improved, and tHcy reduced, using physiological doses $(2 \mu \mathrm{g} /$ day $)$ of B12 for one year [34]. We therefore commenced a randomised 
controlled trial within the cohort as the next logical step to investigate whether improving maternal B12 status improves fetal B12 status and growth, and reduces long term cardio metabolic risk in the next generation.

Previous intervention studies of maternal supplementation started in mid-pregnancy and would have missed the processes that occur around conception and earlygestation such as, gametogenesis, fertilisation, fetal epigenetic reprogramming, embryogenesis, placentation, and organogenesis. We therefore decided to start the intervention pre-conceptionally to influence these processes.

\section{Objectives}

The main objectives are to determine whether preconceptional B12 supplementation of adolescents/young adults:

- improves the B12 status of their new-borns

- improves birth weight, neonatal body composition (increased lean mass and reduced adiposity), insulin sensitivity and cognitive function in the children

- alters the methylome, transcriptome, and metabolome in the cord blood of babies born in the trial.

\section{Methods}

\section{Study population}

The Pune Maternal Nutrition Study (PMNS) was set up in 1993 [25]. At that time, we identified 2,675 married non-pregnant women in 6 villages near Pune for possible enrolment in the study, of whom 2,466 consented to take part. One thousand one hundred and two pregnancies were identified and of these, women with a singleton pregnancy of less than 21 weeks gestation $(n=797)$ entered the study and were assessed for fetal growth, diet and micronutrient status (Fig. 1). The study started in September 1993, the first pregnancy was enrolled in June 1994, and the last delivery occurred in April 1996. Of the 797 mothers enrolled in the study, 12 had spontaneous abortions, 14 terminated their pregnancy, 8 babies were stillborn and 1 mother died during pregnancy. Thus 762 mothers delivered in the study of whom 9 had babies with major congenital anomalies. The remaining children had detailed anthropometry at birth (weight, length, head, mid-upper-arm and abdominal circumferences and skinfolds). Anthropometric data were collected every 6 months, and more detailed measurements of body composition and cardio metabolic risk factors were performed at 6 years, 12 years and 18 years of age (Fig. 2).

Based on the associations between maternal nutrition and cardio metabolic risk in the offspring

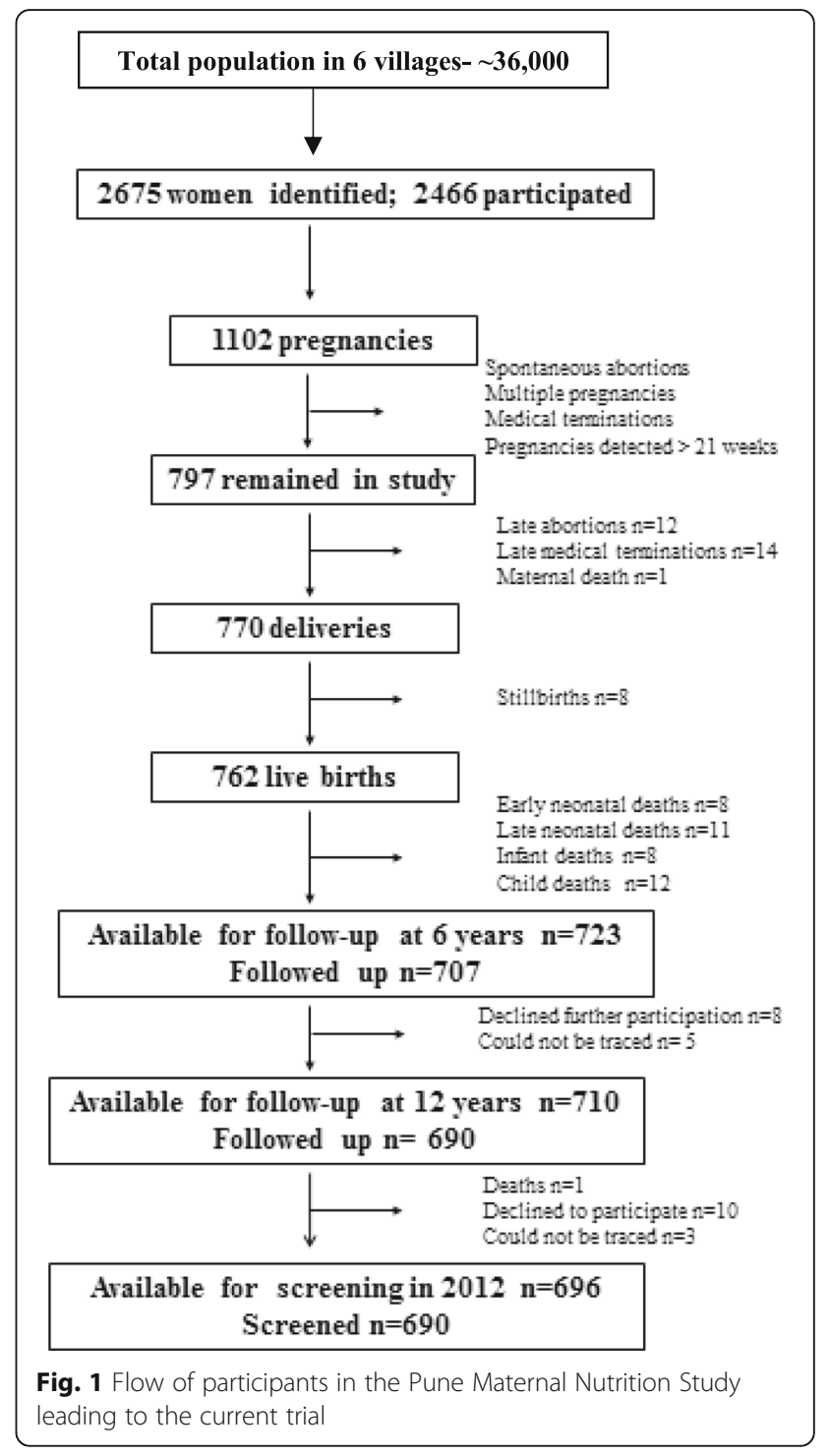

described above, we decided to carry out the micronutrient trial in these boys and girls because they had reached adolescence and we had data across their lifecourse. Recent evidence suggests that the nutritional status of fathers influences epigenetic processes in their offspring [35] and we therefore included boys as well as girls in the trial.

In this rural community, girls were expected to marry and start families quite young. Local statistics showed that, although the legal age of marriage for girls is 18 years, the average age of marriage was 17 , and average age at first delivery 19 . For boys these numbers were 21 and 24 respectively. We anticipated that approximately 180-200 girls (and less than half that number of boys) would marry and have children within four years of starting the trial. 


\section{Pune Maternal Nutrition Study}

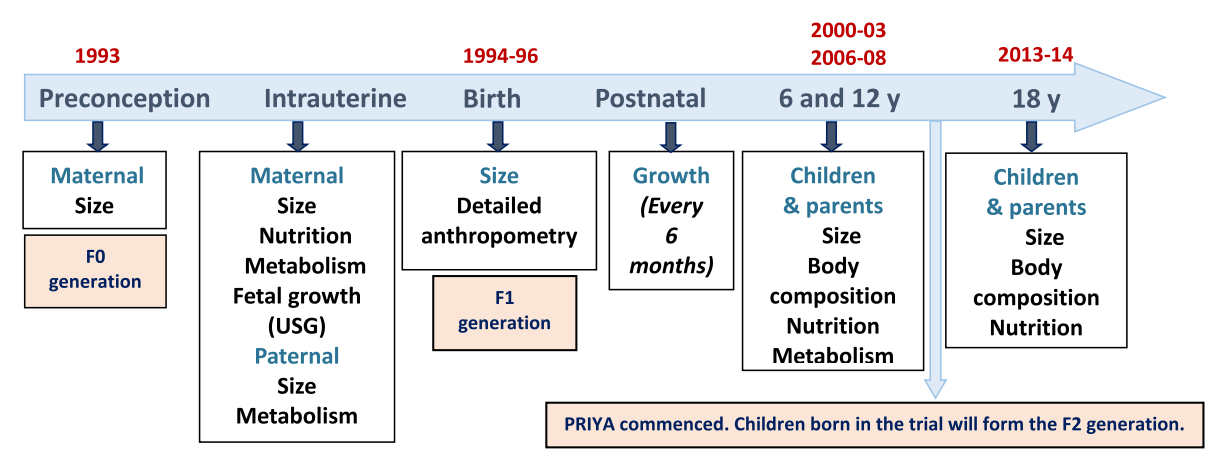

Fig. 2 Measurements and data available at each stage in the Pune Maternal Nutrition Study. A biobank of stored plasma, serum, DNA, urine and stool samples are available from parents (F0) and offspring (F1) at various time points. Cord blood and placenta samples from the children born in the trial (F2) are collected for genetics and epigenetics, immunophenotyping, and microbiota

\section{Study design}

The design is a randomised placebo controlled trial with three arms (Fig. 3). Participants were randomised individually into one of three groups to receive either: i) $2 \mu \mathrm{g}$ B12, ii) $2 \mu \mathrm{g}$ B12 plus multiple micronutrients (MMN) plus $20 \mathrm{~g}$ milk powder (equivalent to $5 \mathrm{~g}$ milk protein), or iii) placebo daily.

The MMN plus protein group is an important pragmatic strategy. Studies in rural India have shown that micronutrient deficiencies are usually multiple and that protein intakes are below recommended levels [25, 36]. We wanted to ensure that other nutritional deficiencies that could limit the effects of B12 alone are covered in one arm of the trial.

We follow the Indian national nutritional anaemia prophylaxis programme guidelines for anaemia prevention [37]. All participants are separately administered weekly iron and folic acid tablets (100 mg iron and $500 \mu \mathrm{g}$ folic acid) and the MMN tablet does not contain these micronutrients. All participants will be treated with a six month course of B12 at the end of the study.

\section{Sample size and power}

We calculated the power of the study from observational data from Pune relating maternal B12 concentrations to cord blood B12 concentrations; a 1 SD higher maternal B12 concentration was associated with a 0.5 SD higher cord blood B12 concentration. Our earlier pilot intervention study (in men, non-pregnant women and children) showed that a dose of $2 \mu \mathrm{g}$ of B12 led to a rise in B12 concentrations of approximately 1 SD over one year, with most of that increase achieved within 4 months [34]. Based on 180-200 pregnancies in the female participants, the trial will have $78-82 \%$ power to detect a change in newborn B12, with B12 supplementation compared with placebo, of $0.5 \mathrm{SD}$, at the $5 \%$ significance level.

Inclusion criteria:

- Adolescents ( 16-18y) belonging to the original PMNS cohort

Exclusion criteria:

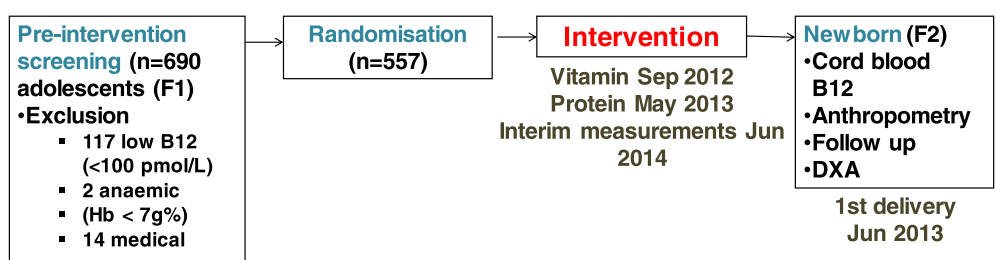

Participants (266 girls and 291 boys) in three groups receive 1) B12 (2mcg), 2) MMN + B12 $(2 \mathrm{mcg})+$ milk powder, or 3) Placebo All receive iron and folate

Duration 3 years or until first delivery

Fig. 3 The design of the Pune Rural Intervention in Young Adults study 
- Severe vitamin B12 deficiency $(<100 \mathrm{pmol} / \mathrm{L})$ or severe anaemia (haemoglobin $<7 \mathrm{~g} / \mathrm{dL}$ ) (due to ethical considerations in a placebo controlled trial)

- Severe physical and mental disability likely to interfere with marriage and reproduction

- Serious systemic illness (that would prohibit participation in any clinical trial e.g., malignancy, reproductive disorder leading to infertility, congenital or acquired cardiovascular disease with New York Heart Association Functional Classification III or IV)

- Treatment with drugs that interfere with 1-C metabolism (e.g., those interfering with folate metabolism such as phenytoin, valproic acid, carbamazepine, trimethoprim, methotrexate and those interfering with B12 absorption such as metformin, proton pump inhibitors)

- Treatment with B12 supplements for more than 30 days at the time of randomisation.

The participants will receive supplements for at least 3 years or until the first delivery (girls) and for the boys, until their wives become pregnant. The children born to these young men and women will be followed up at birth and also later for growth and measurements of diabetes risk markers.

\section{Consenting process}

At the start of the study, detailed information and counselling was provided to the parents and children by investigators, co-investigators or trained social workers at home or in small groups. The children and parents were invited to a local village centre for detailed explanation of the project and the consent process, with transport provided. They had sufficient opportunity to ask questions for further clarification before agreeing to participate. For married participants, we also obtain consent from spouses for collecting cord blood. When obtaining consent from the participants, we have ensured that consent would cover use of the data to examine scientific questions outside the immediate remit of this study, with assurance of anonymity and confidentiality, including archiving of blood and DNA for relevant testing for at least 20 years.

\section{Pre-intervention screening}

A team of investigators, biochemists, medical officer and medical social workers visited the six PMNS villages. Screening procedures included height, weight and blood pressure measurements, a clinical medical examination, and a random blood sample. Of the 696 who were available and approached, 690 underwent screening, 133 were excluded (117 due to severe B12 deficiency $[<100$ $\mathrm{pmol} / \mathrm{L}], 2$ due to severe anaemia $[<7 \mathrm{~g} / \mathrm{dL}]$ and 14 due to medical conditions) leaving 557 eligible participants. Those who were excluded due to severe B12 deficiency and anaemia were treated appropriately.

\section{Randomisation}

The 557 eligible participants were randomised individually into three groups. Randomisation was achieved by a computer generated random sequence numbering system using STATA.

\section{Blinding}

The participants and the study team are blinded to the vitamin/micronutrient supplementation. After randomisation, the list of names of participants in each allocation group was used by an independent staff member not involved in the day-to-day running of the study to package the bottles of capsules into boxes labelled only with the participants' names (not with the allocation group). The bottles of supplements were labelled with the participants' names and ID numbers along with information such as instructions for storage, lot number, expiry date, manufacturer details and a statement that these are for trial purposes and not for sale. The labels clearly highlighted that the contents were for the consumption of the individual named person only. The information on labels was based on guidance from the chair of the scientific advisory committee overseeing the trial. These measures ensured that all members of the research team in direct contact with participants or involved in outcome measurements are completely blinded to the allocation group. The capsule supplements for all groups are identical in appearance. The codified contents of the capsules are in the custody of the Director of Research, KEM Hospital Research Centre, and will be revealed only at the end of the study, except in the case of an emergency medical situation or severe adverse event requiring unblinding. We had a buffer stock of supplements to allow for lost bottles. Bottles of each individual participant were kept in a box labelled with similar information as on the bottles. The log of distribution of individual bottles and date of collection of the previously distributed bottles was maintained for each participant and the information duplicated on these boxes.

The milk powder intervention is not blinded. We initially intended to supply a placebo powder to the other groups, in order to blind the milk powder intervention. However, this was not possible, due to financial constraints. The field workers who distribute the supplements are unaware that it is only the MMN group that receives milk powder. All outcome assessments are done by staff who are blinded to the allocation groups. 


\section{Intervention Product (IP) development}

The dose of vitamin B12 ( $2 \mu \mathrm{g} /$ day $)$ was shown to be efficacious in our pilot trial [34]. The composition of the MMN tablet was guided by the WHO/UNICEF/UNU international multiple micronutrient preparation (UNIMMAP). It provides approximately 1 RDA of a range of vitamins and minerals, except iron and folic acid (which are administered separately to all groups). The final content was based on a pragmatic approach and a balance between Schedule V of the Drug and Cosmetic Act 1945 (amended; [38]), and the ICMR Recommended Dietary Allowance [39]. As the dose of vitamin B12 could not exceed $1 \mu \mathrm{g}$ in a single tablet, to fit in with DCA regulations, we decided to administer two tablets of micronutrients supplements, each containing $1 \mu \mathrm{g}$ of vitamin B12 (Table 1). A reputed local manufacturer was contracted to supply the B12, B12 plus MMN and placebo tablets in batches based on shelf life. Since the micronutrient supplement was considered a nutrient, and not a drug, Food and Drug Administration approval was not necessary.

To comply with the Government programme of weekly supplementation with tablets of iron and folic acid (100 mg of elemental iron and $500 \mu \mathrm{g}$ of folic acid), we took the responsibility of procuring and administering the recommended supplements to all participants.

We originally intended to supply $300 \mathrm{ml}$ of milk to achieve the increase in protein intake. However due to safety and logistical issues, we explored alternative options (nutrient bars, cookies, powder). We eventually decided to administer $20 \mathrm{~g}$ of milk powder (containing $5 \mathrm{~g}$ milk protein) in sachets. This formulation has a good shelf life ( 2 years) and sachets can be distributed along with the micronutrients. The powder can be dissolved either in milk or water to produce a palatable drink.

All intervention products were kept in a separate secure room and the products were accessible only to specific staff members.

\section{Intervention}

The intervention commenced in September 2012. All participants were visited individually and counselled again before being given the supplements. Participants receive supplements on a monthly cycle (with a buffer of 3 extra days' supply). The protein supplements were started in May 2013.

\section{Compliance}

Compliance is being monitored by retrieving the containers of the tablets and counting the number remaining in the container every month. Compliance is encouraged by follow-up telephone calls and a newsletter. We have used the monthly approach successfully in an earlier study which extended over a year, and at the end of which mean compliance remained 80\% [34]. We therefore consider the monthly approach both workable within available resources and effective in our population.

\section{Monitoring of adverse events/morbidity}

Vitamins in the dosages used are not expected to produce any adverse effects. Participants have been encouraged to

Table 1 Contents of the multiple micronutrient supplement tablets, and comparison with the WHO/UNICEF/UNU international multiple micronutrient preparation (UNIMMAP), Schedule $V$ of the Drug and Cosmetic Act (DCA) regulations, and the Indian Council of Medical Research (ICMR) RDA for Indians

\begin{tabular}{|c|c|c|c|c|c|}
\hline & \multirow[t]{2}{*}{ UNIMMAP (1999) } & \multirow[t]{2}{*}{ Schedule V, DCA (2003) } & \multicolumn{2}{|c|}{ ICMR RDA (2010) } & \multirow[t]{2}{*}{ PRIYA } \\
\hline & & & Male & Female & \\
\hline Vitamin A $(\mu \mathrm{g})$ & 800 & $480-750$ & 600 & 600 & 300 \\
\hline Vitamin D (IU) & 200 & $100-200$ & 400 & & 100 \\
\hline Vitamin E (mg) & 10 & $3.35-6.7$ & $7.5-10$ & & 5 \\
\hline Vitamin C (mg) & 70 & $25-50$ & 40 & 40 & 20 \\
\hline Vitamin K ( $\mu \mathrm{g})$ & - & - & 55 & & - \\
\hline Vitamin B1 (mg) & 1.4 & $1-2$ & $1.2-1.7$ & $1.0-1.4$ & 0.75 \\
\hline Vitamin B2 (mg) & 1.4 & $1-3$ & $1.4-2.1$ & $1.1-1.7$ & 0.9 \\
\hline Vitamin B3 (mg) & 18 & $15-26$ & $16-21$ & $12-16$ & 10 \\
\hline Vitamin B6 (mg) & 1.9 & $0.5-1.5$ & 2 & & 0.5 \\
\hline Vitamin B12 $(\mu \mathrm{g})$ & 2.4 & $0.5-1$ & 1.0 & 1.0 & 1.0 \\
\hline Zinc (mg) & 15 & & 12 & 10 & 6 \\
\hline Copper (mg) & 2 & & 2 & & 1 \\
\hline Selenium $(\mu \mathrm{g})$ & 65 & & 40 & & 20 \\
\hline lodine $(\mu \mathrm{g})$ & 150 & & 150 & 150 & 75 \\
\hline
\end{tabular}

Dose in PRIYA 2 capsules/day to achieve $2 \mu \mathrm{g}$ of Vitamin B12; B12 group tablet content is $1 \mu \mathrm{g}$ of Vitamin B12 per capsule; placebo group tablet contains no micronutrients; iron and folic acid given separately to all groups 
contact the field social workers if they feel unwell or experience any adverse events, and in the event of hospitalisation for any reason. Otherwise adverse events and morbidity are monitored on a monthly basis using a standardised questionnaire. All relevant information about any illness is gathered, as well as details of any medication (self-administered or prescribed by a doctor). Serious adverse events (SAE; death, hospital admissions for more than $24 \mathrm{~h}$, debilitating illness) are recorded and investigated by medical personnel overseen by the PI. Regular reports are submitted to the Ethics Committee and the Data Safety Monitoring Board (DSMB). On advice from the DSMB, hospital admission for delivery $(>24 \mathrm{~h})$ is also reported as an SAE, taking into account that it is also the outcome of interest.

\section{Out of area migrations}

Participants who have migrated out of the original PMNS study area (approximately $60 \mathrm{sq}$. km.) but remain within the state of Maharashtra are included in the study. A total of 140 participants had migrated, mainly for education, marriage or work. The majority (105) were within Pune district and less than $70 \mathrm{~km}$ away. However, some had migrated outside the district and live at considerable distances from the study site; the farthest is $\sim 700 \mathrm{~km}$ away. We have modified the distribution of the supplements to every two months for participants who have migrated within the district and participants who have migrated out of the district are given supplements for three months. We expect to be able to collect delivery data even for women who have married outside the study area, as almost all women return to their mother's home for the delivery and for 1-3 months after the birth.

\section{Study events during supplementation}

Interim sample collection We collected an interim sample (at least 6 months after start of supplementation) from April 2013. Its main purpose was to assess the efficacy of the supplementation in improving vitamin B12 status in the different groups. The data were analysed by an independent statistician at the MRC Lifecourse Epidemiology Unit, Southampton and results were sent directly to the Advisory and DSMB Committees, ensuring that investigators remained unaware of results for specific allocation groups. Based on the results, the committees reported to the investigators that the vitamin B12 intervention was efficacious and recommended continuation of the trial.

Marriage and pregnancy After marriage, female participants and wives of male participants are monitored to detect pregnancy. This is being done by the field workers, who monitor menstrual dates. When participants report missing a period, a urine pregnancy test or an ultrasound scan is done to confirm pregnancy.

Once pregnancy is confirmed, the women (including the wives of male participants) are given and advised to take 1 tablet daily of $100 \mathrm{mg}$ iron and $500 \mu \mathrm{g}$ folic acid for 100 days to prevent anaemia, as per Indian Government guidelines. The study supplements are continued among the PMNS girls until their first delivery. Ultrasound scans are carried out at 28 weeks gestation, when blood pressure is also measured, and an OGTT performed (75 g anhydrous glucose). Samples for OMICs studies (blood, breast skin swab and stool) are also collected. Women diagnosed with gestational diabetes are appropriately treated. Local physicians manage the women as per routine standards of care, and we do not become involved unless asked to. We record all concomitant medication, including vitamin supplements.

Husbands of the female participants are offered anthropometric and blood tests at the time of the 28 weeks measurements (hemogram, blood glucose). Wives of the male participants are offered the same tests during pregnancy as the female participants in the study.

Delivery We promote institutional delivery as per Indian Government recommendations. Obstetric care is provided by local doctors. We record relevant events and details of supplements/medication but decisions about obstetric care and management are made by the treating doctor, who is unaware of the allocation group. Maternal blood and samples for microbiota (vaginal swab, breast skin swab, and stool) are collected at delivery. Cord blood is collected for measurement of B12, folate and tHcy, and DNA and RNA samples stored. Placental weight, length and breadth are measured, and samples for molecular biology measurements and histopathology collected. Detailed neonatal anthropometry (including skinfold thickness) is carried out within $72 \mathrm{~h}$. A newborn examination is performed by a paediatrician. Any neonatal medical problems are recorded in a questionnaire, and a newborn stool sample, as soon as possible after birth, is collected for microbiota. Newborns also undergo (since January 2015) a neonatal DXA for detailed body composition measurements.

Post-delivery A paediatrician examines the baby at 28 days post-natally and information on breast feeding, any hospital admissions, and medication during the neonatal period are recorded.

Further plans We originally intended to administer supplements for at least three years or until the first delivery. However, the number of marriages, and consequently pregnancies are lower than expected. Improving 
socioeconomic status and rising educational aspirations are some of the reasons for the later than predicted age of marriage in this rural area. We have therefore extended the study to cover intervention for at least five years or until delivery so that adequate numbers of deliveries take place to enable a proper assessment of the primary outcome. The Chairs of the Advisory and DSMB Committees have advised us that there is no cause for concern in continuing the trial as there are no significant adverse events related to the intervention. We have since secured permission from both ICMR and MRC, and ethical approval from our institutional ethics committee to continue the supplementation for a further two year period. Long-term follow-up, as in the PMNS itself, will start to document the growth and development, and cardiometabolic risk factors of children born in the study.
Laboratory measurements Figure 4 shows the samples collected at various time points. A part of the whole blood sample at all time points (EDTA vacutainer) is transferred to $2 \mathrm{ml}$ micro centrifuge tubes for a haemogram. The remaining blood is centrifuged (2500 $\mathrm{g} \times$ $15 \mathrm{~min}$ ) within an hour of collection, and the separated plasma is stored at $-70{ }^{\circ} \mathrm{C}$ until further analysis. Packed cells are stored for DNA; blood samples for RNA are collected into PAXgene tubes, extracted and stored at $-70{ }^{\circ} \mathrm{C}$. Cord blood is collected after delivery of the baby and clamping the cord. Up to $40 \mathrm{ml}$ of free-flowing cord blood is collected in EDTA and heparin tubes by releasing the cord clamp. The heparin sample is processed for immunophenotyping within $6 \mathrm{~h}$ and the rest is processed as above. Samples for other OMICs studies (microbiota, immunophenotyping) and placental samples are also stored at $-70{ }^{\circ} \mathrm{C}$.

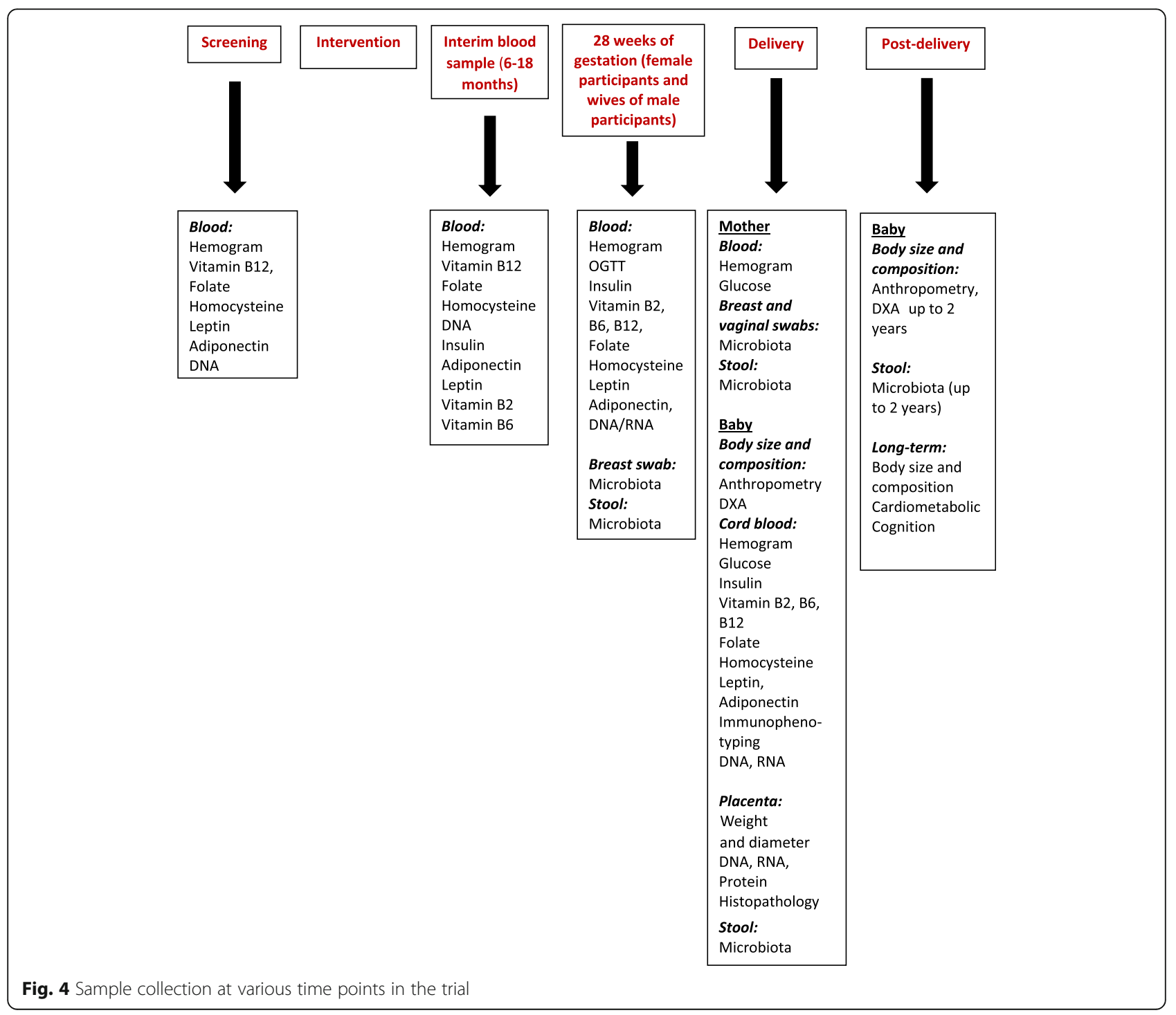


Biochemistry analyses are undertaken for various measurements:

- Hemogram: Beckman Coulter analyser (AC.T diffTM Analyzer, Miami, Florida, USA) on the day of collection.

- Plasma glucose and lipids: Automated biochemistry analyzer (Hitachi 902, Roche Diagnostics, Germany) using standard enzymatic kits.

- Insulin: ELISA kit (Mercodia AB, Uppsala, Sweden).

- Vitamin B2 and B6: standard kits (Recipe Chemicals + Instruments GmbH, Munchen, Germany) using HPLC (PerkinElmer 200 Series, PerkinElmer, Shelton, CT, USA) with fluorescence detector (B2 on whole blood; B6 on plasma).

- Vitamin B12: Microbiological assay using a colistin sulfate-resistant strain of L. Leichmanii.

- Folate: Microbiological assay using a chloramphenicol-resistant strain of L. Casei.

- Total Homocysteine, cysteine and glutathione: HPLC (PerkinElmer 200 Series, PerkinElmer, Shelton, CT, USA) using fluorescence detector.

- Leptin and adiponectin: ELISA kits (Alpco, Salem, NY, USA)

Data analysis The primary short-term outcome (within the period of current funding) is cord blood vitamin B12. Other birth outcomes include birth weight and newborn body composition (by detailed anthropometry in all and by DXA where possible). The trial was set up to examine long-term outcomes, including growth, body composition, glucose and insulin parameters, cardiovascular disease risk markers, and cognitive function at intervals during childhood, and in adult life. The primary analysis will be by 'intention to treat' (ITT), only including newborns whose mothers received micronutrient supplementation for at least 3 months before conception. We will also undertake a per protocol analysis limiting the analysis to babies whose mothers had at least $50 \%$ compliance. We will undertake separate analyses for female and male participants.

We will adjust for vitamin B12 supplements prescribed outside the trial when analysing the primary outcome. We expect that randomisation will generate comparable groups but we will explore the effect of possible confounders and effect modifiers as appropriate for the other outcomes. We will adjust our analyses for maternal age, socio-economic status (before and after marriage), paternal BMI and height, gestational age at birth, and gender of the offspring. We will also examine for possible interaction between allocation group and the following pre-pregnancy factors: maternal BMI, height, age, pre-intervention B12 concentration; pregnancy factors: circulating folate, glucose and lipid concentrations; and fetal factors: newborn sex, and carry out stratified analyses when appropriate.

We will use analysis of variance to test for differences between group means. Appropriate transformations will be used to normalise data if required.

Data management Field methods are regularly subjected to inter-observer and intra-observer variability exercises, and laboratory methods are subject to quality control using in-house methods (duplicates in assays, comparison with local standards) as well as national and international schemes (eg UK NEQAS schemes for insulin and BioRad EQAS schemes for haematology and biochemistry). Data entry is performed using Open Clinica, an open source software for clinical trial data management. Hard copies are checked by research staff, double entered onto computers and checked for quality. Hard data copies are stored in secure filing systems and standard systems are in place to ensure security of electronic formats. Any data transfer not carried out through protected servers is always encrypted. All data is anonymised before analysis and strict confidentiality is maintained. Analysis files (e.g., STATA or SPSS) are issued by the data manager only after approval from the PI, and a $\log$ is maintained.

Governance We have gone to special lengths to clarify and discuss the ethical aspects of this study including the issues around conducting a placebo controlled trial in a community with substantial B12 deficiency as per international criteria. From a public health perspective, randomised studies are important because low B12 concentrations are common, and if B12 supplementation of mothers has clear benefits, this would indicate the need for national level intervention. On the other hand, from an individual point of view, it could be unethical not to treat people who, although apparently healthy, have B12 concentrations considered insufficient by international standards. The concept of a randomised controlled trial is unfamiliar to the villagers in our setting, many of whom are poorly educated and tend to trust medical professionals unquestioningly. We held a series of three meetings in Pune with $\sim 30$ lay people and scientists from different disciplines, focus group discussions with villagers, and meetings with a village Community Advisory Group made up of elders/leaders, teachers and participants in our research. We have also individually consulted experts in nutrition and public health research. The consensus was that the intervention study should proceed, because of the public health importance of getting an answer, combined with the individual-level considerations that a) the low B12 concentrations in this population are sub-clinical and evidence of its detrimental health effects is currently only observational and 
limited to risk markers; b) supplementation with B12 in the pilot trial produced no changes in haemoglobin concentration or other measurable individual health benefits; c) participants with B12 concentrations $<100$ pmol/l will be excluded and treated with B12 supplements, and d) the placebo group (all participants) will receive a 6 month course of B12 supplements at the end of the trial.

We also commissioned a study in the villages by an independent social scientist to explore the community's understanding of research which suggested ways in which the study could be better explained to the participants. We have incorporated these findings in designing the information leaflets.

We follow ICMR and MRC (UK) guidelines for the ethical conduct of biomedical research. We have appointed a Scientific Advisory Committee (SAC) and a Data Safety Monitoring Board (DSMB) to oversee the trial, with appropriate membership. The Scientific Advisory Committee consists of clinicians, social scientists and medical administrators. The DSMB includes an epidemiologist, statistician, social scientist and nutritionist. Both are chaired by independent scientists with high level leadership experience in India. The SAC provides advice on the scientific aspects and conduct of the trial, and monitors its progress. The DSMB reviews data collection and quality, adherence to study protocol, safety records and adverse events and advises on further course of action including trial continuation. Reports are submitted every six months to both committees and a face-to-face meeting takes place annually. The trial has been registered with the CTRI (2012/12/003212) and ISRCTN (32921044).

Dissemination Our main target audience will be the scientific community working in related fields. We will disseminate our findings through peer reviewed publications and presentations at national and international seminars/conferences. We will also extend our dissemination to scientists in other disciplines to whom our work will be relevant such as economists and agricultural scientists. We aim to publish our work in open access format. We will also engage with Indian and international policy makers. Members of our collaborative group are linked into national and international policy advisory groups such as the Indian Council of Medical Research, Department of Biotechnology (India), FIGO, WHO and UNICEF and we will ensure relevant findings are disseminated through these groups to influence policy.

As our participants are healthy volunteers, informing them about our findings has gained their support. Our research topics, including pregnancy, child health, and common adult disorders, are of general interest. We share information through community meetings, information leaflets and newsletters, and one-to-one feedback. We also disseminate our research to the wider public through a variety of mass media.

\section{Discussion}

Our study tests a primordial prevention strategy through an intergenerational intervention started preconceptionally in both boys and girls using physiological doses of micronutrients to improve immediate pregnancy-related and long-term cardio metabolic outcomes. The results of our study will have potentially significant public health implications in an area where B12 deficiency is relatively common but folate deficiency is rare. The within cohort design and detailed information available will allow us to understand the lifecourse evolution of non-communicable diseases, and the randomised design will allow us to understand causal relationships.

\begin{abstract}
Acknowledgements
We are grateful to all our participants for their help over the years, and during this study. We appreciate the advice of Dr AS Nanivadekar and Dr M Gupte, the chairs of our Scientific Advisory Committee and Data Safety and Monitoring Board respectively. We thank Dr VS Padbidri and Dr L Garda, former and current Directors of Research, KEM Hospital Research Centre, and Dr KJ Coyaji, Director of KEM Hospital for their support. We also thank the staff of the Diabetes Unit for their help in conducting the study, particularly Dr U Deshmukh, S Bagate, A Bhalerao, S Chaugule, R Dendge, T Deokar, M Gaikwad, N Gurav, S Jagtap, J Kalokhe, S Pandit, N Memane, F Rajgara, D Raut, L Ramdas, M Raut, R Saswade, and V Solat. We thank Ella Marley-Zagar, statistician, for independent data analyses for the DSMB. We are grateful to the Indian Council of Medical Research and the Medical Research Council, UK for their support. We also acknowledge the contributions of the Department of Biotechnology, India and the Wellcome Trust, UK. We acknowledge the support of Dr ND Deshmukh and the Zilla Parishad, Pune.
\end{abstract}

\section{Funding}

The main trial is funded by the Indian Council of Medical Research (58/1/8/ MRC-ICMR/2009/NCD-II) and Medical Research Council, UK (MR/J000094/1) as part of an Indo-UK collaborative call (grant title: Maternal B12, folate and homocysteine as determinants of inter-generational programming of diabesity: a community-based randomised controlled trial). The original Pune Maternal Nutrition Study (PMNS) is funded by the Wellcome Trust, UK (038128/Z/93) and so are the two follow-ups at 6 and 12 years (059609/Z/99 and 079877/Z/06/Z respectively). The sample collection for omics and initial measurements are funded by a centre of excellence grant from the Department of Biotechnology, Government of India (BT/01/CEIB/12/II/10). The funders do not have any role in the study design; data collection, management, analysis, and interpretation of data; writing of the report; and the decision to submit for publication.

Availability of data and materials

Not applicable.

\section{Authors' contributions}

CY and CF conceptualised the study. KK, PY, HL, CJ, DB, CF and CY contributed to the study design and development of the trial protocol, and are involved in the conduct of the trial. PK, SJ, and RL are involved in the conduct of the trial. KK, CF and CY wrote the first draft of the manuscript; $P Y$, $\mathrm{HL}, \mathrm{CJ}, \mathrm{DB}, \mathrm{PK}, \mathrm{SJ}$ and RL critically reviewed the manuscript. CY is the guarantor of the study. All authors read and approved the final manuscript.

Competing interests

The authors declare that they have no competing interests. 


\section{Consent for publication}

Not applicable.

\section{Ethics approval and consent to participate}

The study has been approved by the Ethics Committee of the KEM Hospital Research Centre, Pune (October 2011; no. 1112A). The committee is registered with the Drug Controller of the Government of India and its membership follows ICMR guidelines and is composed of a total of 11 members (2 clinicians, 3 scientists, 2 legal experts, 2 social scientists, 1 NGO representative and 1 lay person).

We have also obtained permission from the Zilla Parishad (local governmental authority) who is responsible for the health of the community (February 2012). All foreign collaborative studies in India need the permission of the HMSC (Health Ministry Screening Committee) which we have obtained (November 2011).

As the participants were all under 18 at the start of the study, written consent was obtained from the parents and assent from the children. It was made clear they could withdraw at any time during the study even if written consent had been given. In addition, children signed their own consent when they reached the age of 18 years.

\section{Publisher's Note}

Springer Nature remains neutral with regard to jurisdictional claims in published maps and institutional affiliations.

\section{Author details}

'Diabetes Unit, KEM Hospital Research Centre, Rasta Peth, Pune 411011, India. ${ }^{2} \mathrm{MRC}$ Lifecourse Epidemiology Unit, University of Southampton, Southampton SO16 6YD, UK.

\section{Received: 28 December 2016 Accepted: 4 March 2017 Published online: 08 May 2017}

\section{References}

1. Hales CN, Barker DJP. Type 2 (non-insulin-dependant) diabetes mellitus : the thrifty phenotype hypothesis. Diabetologia. 1992;35:595-601.

2. Hales CN, Barker DJP, Clark PMS, Cox LJ, Fall CHD. Fetal and infant growth and impaired glucose tolerance at age 64 years. BMJ. 1991;303:1019-22.

3. Mi J, Law C, Zhang KL, Osmond C, Stein C, Barker D. Effects of infant birthweight and maternal body mass index in pregnancy on components of the insulin resistance syndrome in China. Ann Intern Med. 2000;132:253-60.

4. Fall CHD, Stein CE, Kumaran K, Cox V, Osmond C, Barker DJP, Hales CN. Size at birth, maternal weight and type 2 diabetes in South India. Diabet Med. 1998;15:220-7

5. Eriksson JG, Forsen T, Tuomilehto HJ, Barker DJP. Early growth and coronary heart disease in later life: longitudinal study. BMJ. 2001;322:949-53.

6. Victora CG, Adair L, Fall C, Hallal PC, Martorell R, Richter L, Sachdev HPS, for the Maternal and Child Undernutrition Study Group. Maternal and child undernutrition: consequences for adult health and human capital. Lancet. 2008;371:340-57.

7. Whincup PH, Kaye SJ, Owen CG, Huxley R, Cook DG, Anazawa S, BarrettConnor E, Bhargava SK, Birgisdottir B, Carlsson S, De Rooij S, Dyck R, Eriksson JG, Falkner B, Fall CHD, Forsen T, Grill V, Gudnason V, Hulman S, Hypponen E, Jeffreys E, Lawlor D, Leon D, Mi J, Minami J, Mishra G, Osmond C, Power C, Rich-Edwards J, Roseboom TJ, Sachdev HPS, Suzuki T, Syddall H, Thorsdottir I, Vanhala M, Wadsworth M, Yarbrough DE. Birthweight and risk of type 2 diabetes: a quantitative systematic review of published evidence. JAMA. 2008:300:2885-97.

8. Eriksson JG, Forsen T, Tuomilehto J, Osmond C, Barker DJP. Early adiposity rebound in childhood and risk of type 2 diabetes in adult life. Diabetologia. 2003:46:190-4

9. Gardner DS, Jackson AA, Langley-Evans SC. The effect of prenatal diet and glucocorticoids on growth and systolic blood pressure in the rat. Proc Nutr Soc. 1998;57:235-40.

10. Warner MJ, Ozanne SE. Mechanisms involved in the developmental programming of adult disease. Biochemistry J. 2010;427:333-47.

11. Kinra S, Sarma KVR, Ghafoorunissa, Mendu WR, Ravikumar R, Mohan V, Wilkinson IB, Cockroft JR, Davey Smith G, Ben-Shlomo Y. Effect of integration of supplemental nutrition with public health programmes in pregnancy and early childhood on cardiovascular risk in rural Indian adolescents: long term follow-up of Hyderabad nutrition trial. BMJ. 2008;337:a605.

12. Vaidya A, Saville N, Shrestha BP, Costello AM, Manandhar DS, Osrin D. Effects of a maternal multiple micronutrient supplement on children's weight and size at 2 years of age in Nepal; follow-up of a double blind randomised controlled trial. Lancet. 2008;371:452-4.

13. Hawkesworth S, Prentice A, Fulford A, Moore S. Maternal protein-energy supplementation does not affect adolescent blood pressure in the Gambia. Int J Epidemiol. 2008;38:119-27.

14. Tarry-Adkins $J$, Ozanne $S$. Mechanisms of early life programming: current knowledge and future directions. Am J Clin Nutr. 2011;94(suppl):1765S-71.

15. Burdge GC, Lillycrop KA. Nutrition, epigenetics, and developmental plasticity: implications for understanding human disease. Ann Rev Nutr. 2010;30:315-39.

16. Waterland RA, Jirtle RL. Transposable elements: Targets for early nutritional effects on epigenetic gene regulation. Mol Cell Biol. 2003;23:5293-300.

17. Heijmans BT, Tobi EW, Stein AD, Putter H, Blauw GJ, Susser ES, Slagboom PE, Lumey LH. Persistent epigenetic differences associated with prenatal exposure to famine in humans. Proc Natl Acad Sci U S A. 2008;105:17046-9.

18. Steegers-Theunissen RP, Obermann-Borst SA, Kremer D, Lindemans J, Siebel C, Steegers EA, Slagboom PE, Heijmans BT. Periconceptional maternal folic acid use of 400 micrograms per day is related to increased methylation of the IGF2 gene in the very young child. PLoS One. 2009;4:e7845.

19. Godfrey KM, Sheppard A, Gluckman PD, Lillycrop KA, Burdge GC, McLean C, Rodford J, Slater-Jefferies JL, Garratt E, Crozier SR, Emerald BS, Gale CR, Inskip HM, Cooper C, Hanson MA. Epigenetic gene promoter methylation at birth is associated with child's later adiposity. Diabetes. 2011;60:1528-34.

20. Relton CL, Groom A, St Pourcain B, Sayers AE, Swan DC, Embleton ND, Pearce MS, Ring SM, Northstone K, Tobias JH, Trakalo J, Ness AR, Shaheen SO, Davey SG. DNA methylation patterns in cord blood DNA and body size in childhood. PLoS One. 2012;7:e31821.

21. Waterland RA, Kellermayer R, Laritsky E, Rayco-Solon P, Harris RA, Travisano M, Zhang W, Torskaya MS, Zhang J, Shen L, Manary MJ, Prentice AM. Season of conception in rural Gambia affects DNA methylation at putative human metastable epialleles. PLoS Genet. 2010;23:e1001252.

22. Dominguez-Salas P, Moore SE, Baker MS, Bergen AW, Cox SE, Dyer RA, Fulford AJ, Guan Y, Laritsky E, Silver MJ, Swan GE, Zeisel SH, Innis SM, Waterland RA, Prentice AM, Hennig BJ. Maternal nutrition at conception modulates DNA methylation of human metastable epialleles. Nat Commun. 2014. doi:10.1038/ncomms4746.

23. Ramachandran P. Maternal nutrition - effect on fetal growth and outcome of pregnancy. Nutr Rev. 2002;60:S26-34.

24. International Diabetes Federation. IDF Diabetes Atlas. 7th ed. Brussels: International Diabetes Federation; 2015. http://www.idf.org/diabetesatlas.

25. Rao S, Yajnik CS, Kanade A, Fall CH, Margetts BM, Jackson AA, Shier R, Joshi $\mathrm{S}$, Rege $\mathrm{S}$, Lubree $\mathrm{H}$, Desai $\mathrm{B}$. Intake of micronutrient-rich foods in rural Indian mothers is associated with the size of their babies at birth. J Nutr. 2001;131:1217-24

26. Modi N, Thomas EL, Uthaya SN, Umranikar S, Bell JD, Yajnik C. Whole body magnetic resonance imaging of healthy newborn infants demonstrates increased central adiposity in Asian Indians. Pediatr Res. 2009;65:584-7.

27. Yajnik CS, Lubree HG, Rege SS, Naik SS, Deshpande JA, Deshpande SS, Joglekar CV, Yudkin JS. Adiposity and hyperinsulinemia in Indians are present at birth. J Clin Endocrinol Metab. 2002;87:5575-80.

28. Yajnik CS, Fall CHD, Coyaji KJ, Hirve SS, Rao S, Barker DJP, Joglekar C, Kellingray S. Neonatal anthropometry: the thin-fat Indian baby. The Pune Maternal Nutrition Study. Int J Obesity. 2003;27:173-80.

29. Yajnik CS, Deshpande SS, Panchanadikar AV, Naik SS, Deshpande JA, Coyaji $\mathrm{KJ}$, Fall CHD, Refsum H. Maternal total homocysteine concentration and neonatal size in India. Asia Pac J Clin Nutr. 2005;14:179-81.

30. Yajnik CS, Chandak GR, Joglekar C, Katre P, Bhat DS, Singh SN, Janipalli CS, Refsum H, Krishnaveni G, Veena S, Osmond C, Fall CH. Maternal homocysteine in pregnancy and offspring birthweight: epidemiological associations and Mendelian randomization analysis. Int J Epidemiol. 2014;43: 1487-97.

31. Yajnik CS, Deshpande SS, Jackson AA, Refsum H, Rao S, Fisher DJ, Bhat DS, Naik SS, Coyaji KJ, Joglekar CV, Joshi N, Lubree HG, Deshpande VU, Rege SS, Fall CHD. Vitamin B12 and folate concentrations during pregnancy and insulin resistance in the offspring: The Pune Maternal Nutrition Study. Diabetologia. 2008:51:29-38. 
32. Stewart CP, Christian P, Schulze KJ, Arguello M, LeClerq SC, Khatry SK, West KP. Low maternal vitamin B12 status is associated with offspring insulin resistance, regardless of micronutrient supplementation, in rural Nepal. J Nutr. 2011:141:1912-7.

33. Bhat DS, Thuse NV, Lubree HG, Joglekar CV, Naik SS, Ramdas LV, Johnston C, Refsum H, Fall CH, Yajnik CS. Increases in plasma holotranscobalamin can be used to assess vitamin B-12 absorption in individuals with low plasma vitamin B-12. J Nutr. 2010;139:2119-23.

34. Deshmukh US, Joglekar CV, Lubree HG, Ramdas LV, Bhat DS, Naik SS, Hardikar PS, Raut DA, Konde TB, Wills AK, Jackson AA, Refsum H, Nanivadekar AS, Fall CH, Yajnik CS. Effect of physiological doses of vitamin B12 on plasma homocysteine; a randomised placebo-controlled doubleblind trial in India. Eur J Clin Nutr. 2010;64:495-502.

35. Curley JP, Mashoodh R, Champagne FA. Epigenetics and the origins of paternal effects. Horm Behav. 2011;59:306-14.

36. Chakravarty I, Sinha RK. Prevalence of micronutrient deficiency based on results obtained from the national pilot program on control of micronutrient malnutrition. Nutr Rev. 2002;60:S53-8.

37. Guidelines for control of iron deficiency anaemia. Ministry of Health and Family Welfare, Government of India. 2013. http://www.pbnrhm.org/docs/ iron_plus_guidelines.pdf. Accessed 25 Oct 2016.

38. The Drug and Cosmetic Act and Rules. Ministry of Health and Family Welfare, Government of India. 2005. http://www.cdsco.nic.in/writereaddata/ Drugs\&CosmeticAct.pdf . Accessed 4 May 2017.

39. Nutrient requirements and recommended dietary allowances for Indians. A report of the expert group of the Indian Council of Medical Research. National Institute of Nutrition, Hyderabad, India. 2010. http://icmr.nic.in/final/ rda-2010.pdf. Accessed 25 Oct 2016

\section{Submit your next manuscript to BioMed Central and we will help you at every step:}

- We accept pre-submission inquiries

- Our selector tool helps you to find the most relevant journal

- We provide round the clock customer support

- Convenient online submission

- Thorough peer review

- Inclusion in PubMed and all major indexing services

- Maximum visibility for your research

Submit your manuscript at www.biomedcentral.com/submit 